\title{
The impact of knowledge transfer on the Organizational performance
}

\author{
Francisca - Elena ZAMFIR \\ Bucharest University of Economic Studies, Bucharest, Romania \\ zamfir.francisca@yahoo.com
}

\begin{abstract}
While the importance of knowledge creation and management has been widely recognized as critical to the continued competitiveness and success of an organization since the 1990s, few systematic studies have been conducted on the processes of creation and knowledge management transfer in organizations. Much of what has been reported in the literature has an anecdotal nature. The development of knowledge management as a distinct domain has historically been influenced by research undertaken in a wide range of disciplines. These disciplines include sociology, psychology and philosophy. Since the early 1990s, research in the area of knowledge management has expanded into contiguous areas such as change management, systems theory, organizational theory, organizational learning \&development and artificial intelligence. During the past years, there has been a great deal of interest in knowledge as an organizational and commercial variable, with the need to better understand the processes of knowledge transfer in organizations. In this paper, I present and develop the following questions: What kind of knowledge should we transfer? How should we transfer knowledge between entities? What is the impact of knowledge transfer on organizational performance? To develop the previously mentioned questions, a quantitative research based on a questionnaire has been applied on a sample of 100 people who are working in a certain shared services centre. The main purpose of the research is to identify the impact of knowledge sharing on organizational performance and to analyze the importance of having a solid base of information in order to achieve excellent organizational performance. The result is that knowledge transfer has an impact on the company's vision, continuous learning and business performance. The way knowledge is managed in a company is crucial to gain a competitive advantage, this being recognized by the respondents as important for achieving the following goals: project success and self-improvement.
\end{abstract}

Keywords: knowledge transfer, knowledge management, organizational performance.

\section{Introduction}

The development of knowledge management as a distinct domain has historically been influenced by research in a wide range of disciplines. These disciplines include sociology, psychology and philosophy. Over the past five to ten years, thinking in the area of knowledge management has been influenced and extended by contiguous areas such as change management, leadership development, systems theory, organizational theory, organizational development, organizational learning and artificial intelligence.

In this paper, I study two dimensions of knowledge transfer -what and how bydeveloping these questions: What kind of knowledge should we transfer? How should we transfer knowledge between entities? What is the impact of knowledge transfer on organizational performance?

The main purpose of the research is to identify the impact of knowledge sharing on organizational performance to better carry out knowledge transfer sessions and to analyze the importance of having a solid information base in order to be able to offer superior service to customers, a factor that contributes to the achievement of excellent organizational performance. 
In addition, this research aims to identify the needs of employees on knowledge transfer, to work better together, to develop their careers, to learn their perception regarding career success and what organizational performance represents for them.

With the data from the research, we will learn what is the perception of the employees of a shared services centre, opened in Bucharest in 2017, on the importance of knowledge transfer in connection with organizational performance.

PICBE $\mid 578$

In addition, we will learn what is the role of the company on organizational performance, how it helps employees to develop and train, and what is the importance of feedback in order to improve the quality of provided services for the organizational performance.

\section{Literature review}

\section{Knowledge management overview}

The term knowledge is not easy to define, although many authors have attempted to do so. These definitions describe the characteristics, dimensions and principles of knowledge and reveal the complexity of the factors affecting the development and movement of knowledge.

Organizations, at least as we know them, were born in the industrial age. Since that time, research has focused on understanding how to make people in the organization more effective. One of the first references on the impact of knowledge on organizations was made by Polanyi (1966), who identified the fact that each "element" of knowledge has two dimensions, a tacit dimension and an explicit.

\section{Tacit and explicit dimensions of knowledge}

Drawing on the work of Polanyi (1966) 18, Nonaka and Takeuchi (1995) have made one of the most important contributions to our understanding of knowledge in organizations by describing the different types of knowledge. In short, they claimed that there were two types of knowledge: explicit knowledge and tacit knowledge.

Explicit knowledge can be expressed in words and numbers and shared in the form of data, scientific formulas, specifications, etc. This type of information can be easily transmitted between individuals in a formal and systematic manner.

On the other hand, tacit knowledge is very personal and difficult to formalize, which makes it difficult to share it with others. Subjective ideas, hunches and hunches fall into this category of knowledge. Tacit knowledge is deeply rooted in an individual's actions and experiences, as well as in the ideals, values or emotions they embrace.

To access knowledge, it is necessary to exploit the tacit and subjective information of each employee, and this information must be made available for use throughout the company. Nonaka and Takeuchi consider business as a living organism endowed with a collective sense of identification, equivalent to self-knowledge in an individual. This requires that the organization becomes able to share tacit and explicit knowledge according to four basic models:

- Tacit to tacit. From one individual to another as in the role of master apprentice;

- Explicit to explicit. Combine pieces of desirable explicit knowledge into a new set, that is, create reports on the financial condition of businesses by collecting the items from each organizational unit;

- Tacit to explicit. An individual who shares and articulates tacit knowledge makes it easily accessible to all; 
- Explicit to tacit. As individuals gain a better understanding of shared explicit knowledge, it is useful to create a cognitive bridge with their own tacit knowledge base which can create or expand a new dimension of tacit knowledge.

Organizational performance is one of the most important variables in management research and arguably the most important indicator of an organization's success.

A review of the literature reveals that many factors affect the efficiency of knowledge transfer processes. The most commonly cited factors are illustrated in the Figure 1 below.

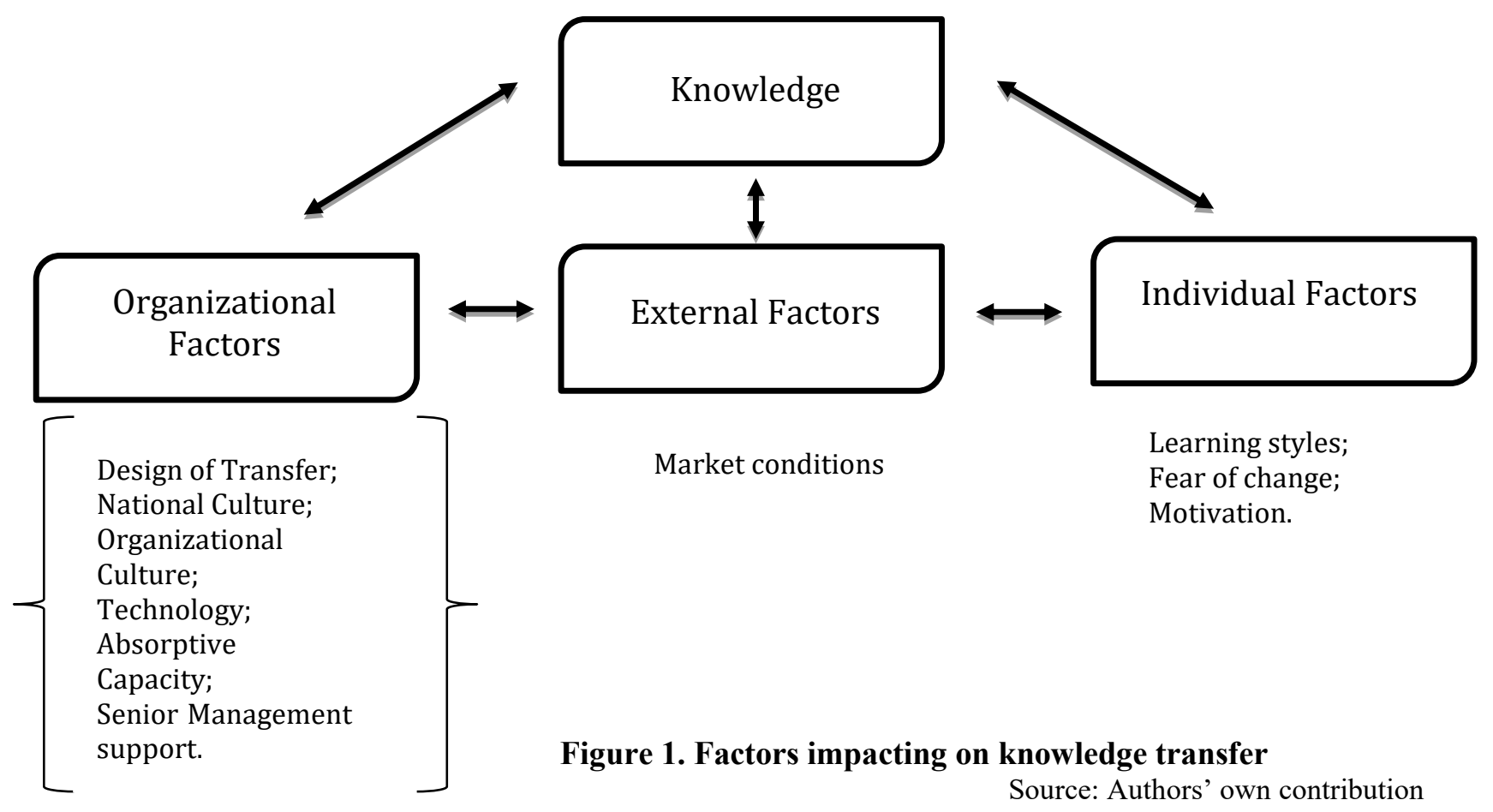

Knowledge management is essential for organizations to create a sustainable competitive advantage. In addition, knowledge management initiatives help improve business processes. Organizations can reduce the time it takes to process cases simply because they can share best practices. Processes can also be improved through conversations and discussions that can generate valuable knowledge for expected savings and cost reduction.

The importance of performance for professional organizations can be seen through the following points:

- successful organizations are characterized by their ability to improve elements of organizational performance, as this often results from knowledge processes that reflect the nature of leadership and the values of diversity and continuous development;

- the survival of organizations in a particular market is linked to the level of performance and, therefore, the organizations that are particularly interested in the issue of performance will remain the same as long as you wish to remain active in the business environment. 


\section{Methodology}

To show the impact of knowledge sharing on organizational performance, I chose to do quantitative research, using the questionnaire. Also, I did an analysis on the key performance indicators for the shared services centre team that is in charge with personnel administration for the North America entity the group. This analysis composes a comparison between the performance of this team for the year 2018 - the second year of activity of this team - and the year when the team has had knowledge transfer sessions with the local teams in North America.

To carry out the survey, I applied the questionnaire to 100 people, employed at the shared services centre. The people who took part in this survey are people aged between 20 and 50, therefore representatives of the various departments (human resources, finance, data management, etc.). In addition, the questionnaire has 15 questions.

To show the impact of knowledge sharing on organizational performance, I formulated four hypotheses:

1. Employees consider that knowledge transfer helps them to understand tools and processes, which increases their productivity, the quality of their services and has a positive impact on the performance of the organization.

2. There is a significant relationship between knowledge management and organizational performance.

3. The company plays a very important role in the performance of each employee who contributes to the achievement of excellent organizational performance.

4. The transfer of knowledge has an impact on the vision of the company, management based on skills, continuous learning and the performance of the company.

\section{Results and discussions}

The presentation of the results begins with the visualization of the characteristics of the respondents. A number of 101 individuals responded to the questionnaire that addresses the impact of knowledge sharing on organizational performance, which number is comprised of 79 responses from women and 22 from men. Regarding their age, it can be noted that the youngest employees (who are between 18 and 24 years old) have shown a greater interest in this subject. The statistics are shown in Figure 2 below.

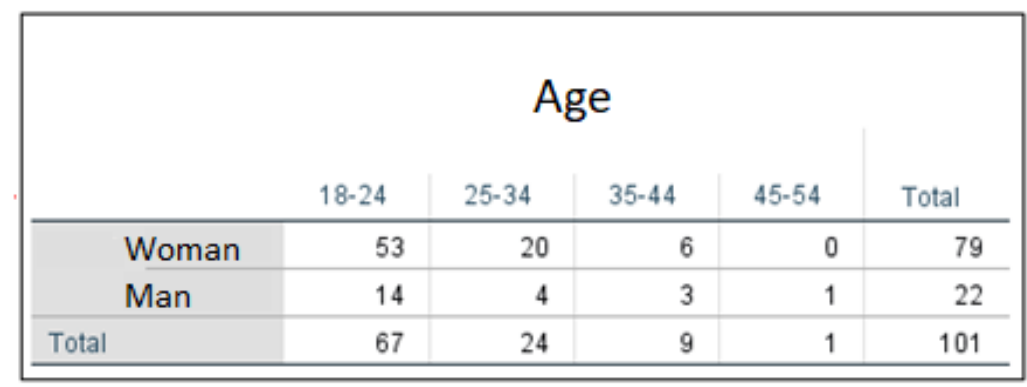

Figure 2. Characteristics of respondents - gender and age

Source: Authors' own research resultsafter entering data in SPSS 
Similarly, employees who are in the early stages of their careers have expressed their voices on the importance of knowledge sharing. We can notice that a number of 45 employees who have entry-level functions have given their opinion and they are followed by a number of 35 employees who occupy intermediate level functions. In addition, employees who are part of the human resources department contributed in large numbers to the completion of this survey (42 respondents from the human resources department). The figures are shown in Figure 3 below.

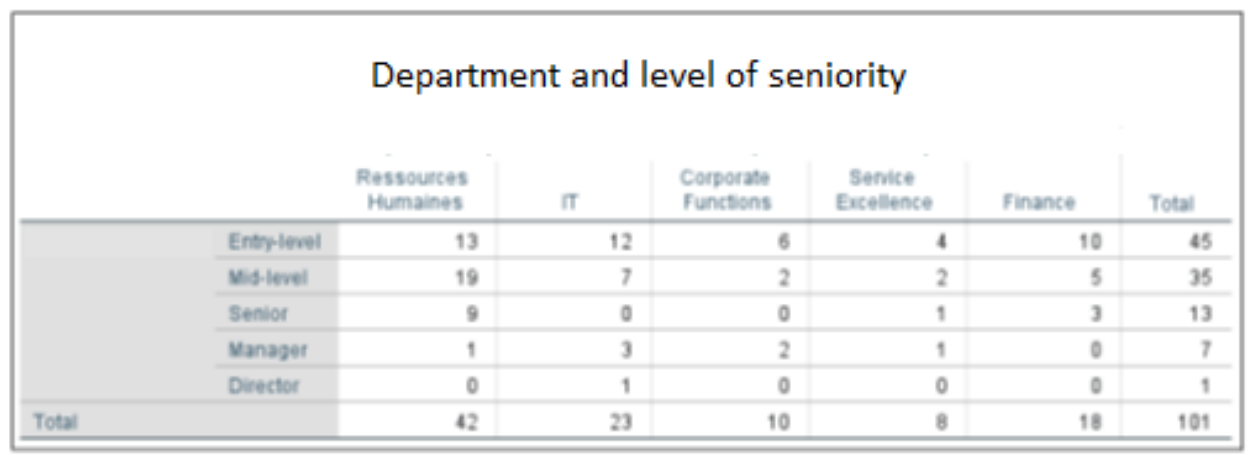

Figure 3. Characteristics of respondents -department and level of seniority

Source: Authors' own research resultsafter entering data in SPSS

The first hypothesis which aims at the importance of knowledge transfer for employees (impact on productivity, performance and quality of services) is demonstrated in the following lines.

In Figure 4 we can notice that the employees of the shared services centre consider that the transfer of knowledge plays an important role on the constant and continuous transformation of the learning of each individual of the company, a factor which has a great impact on organizational performance. $58.42 \%$, or more than half, agreed with the aspect presented below.

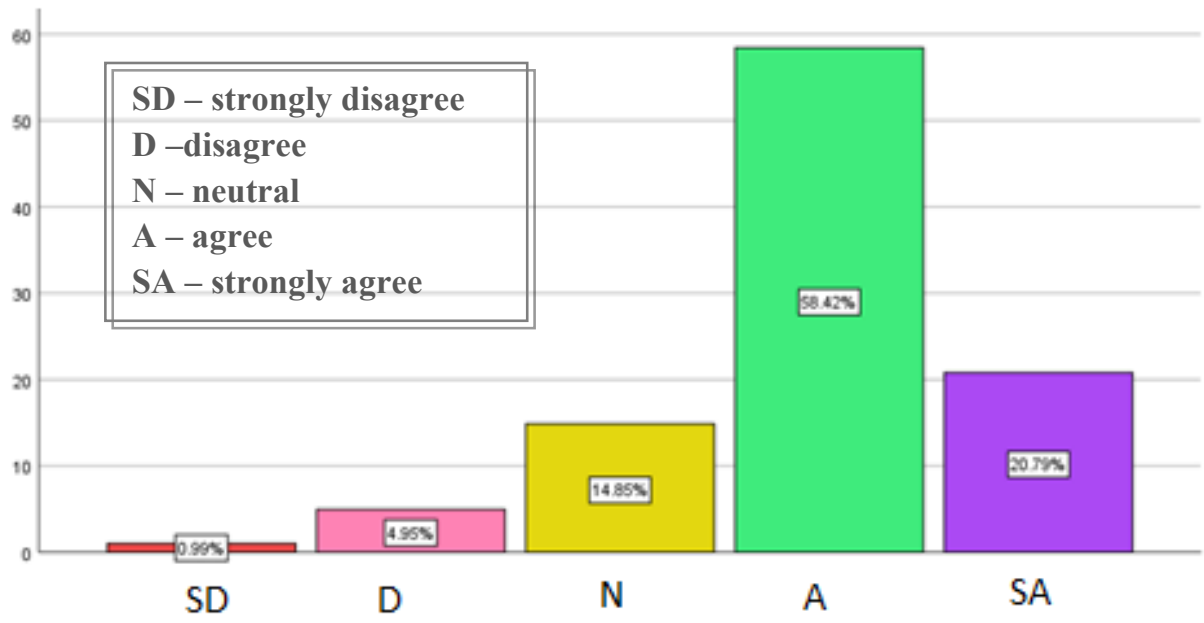

Figure 4. Organizational learning

Source: Authors' own research results after entering data in SPSS 
People learn and induce from previous experiences. We first learn how to use a spoon and then learn how to use forks of different sizes. We first learn to sew and then learn to embroider. Transferring knowledge from one situation to another related situation often increases the speed and quality of learning. This observation is relevant for human learning, as well as machine learning.

In Figure 5 we see that $66.34 \%$ of employees agree that knowledge management contributes to improving productivity and / or quality of service, while $24.75 \%$ are in total agreement.

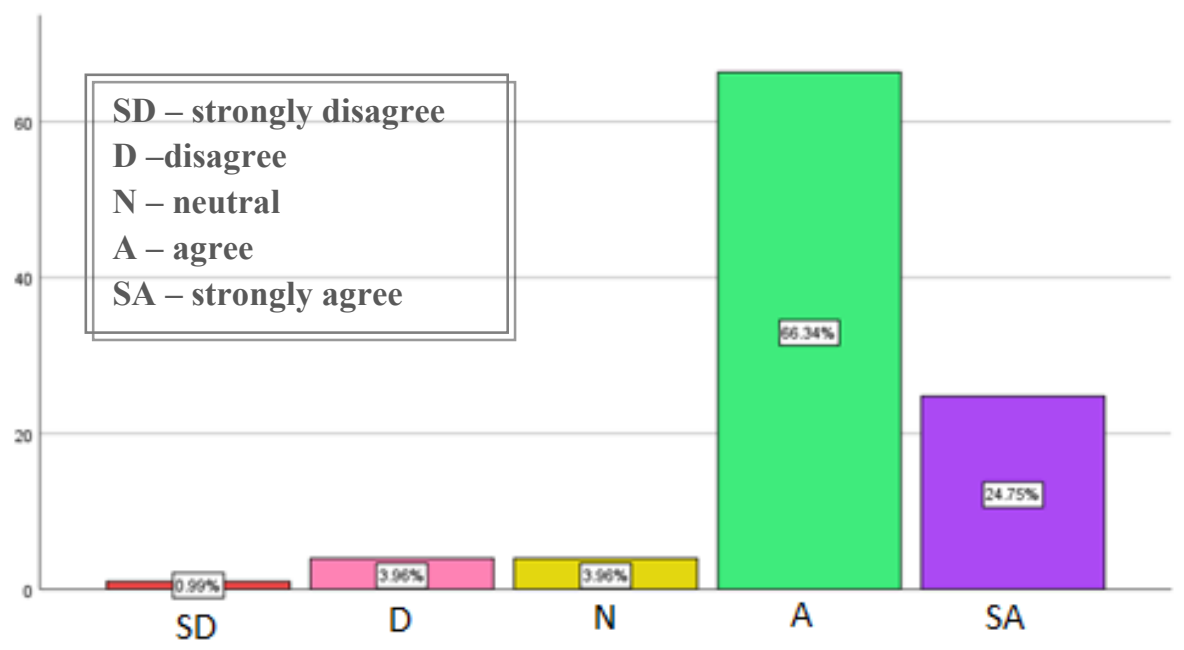

Figure 5. The impact on productivity and quality of service

Source: Authors' own research results after entering data in SPSS

Continuous improvement is seen as a difficult task. The challenge is to capture and store knowledge and learn from one individual to another and from one project to another. Today's organizations are faced with a complex and constantly changing environment. To solve problems and succeed, the project-based working method is adopted, which is more flexible and innovative. Projects have flexibility and fluidity, which is a necessity to adapt to the rhythm of circumstances. In addition, projects are seen as creative entities, generating and applying new knowledge, which can undoubtedly be useful, transferred and shared in and between projects and in the context of the company, a fact which is represented in figure 6 and which is valid for $60.40 \%$ of the employees (they agree). 


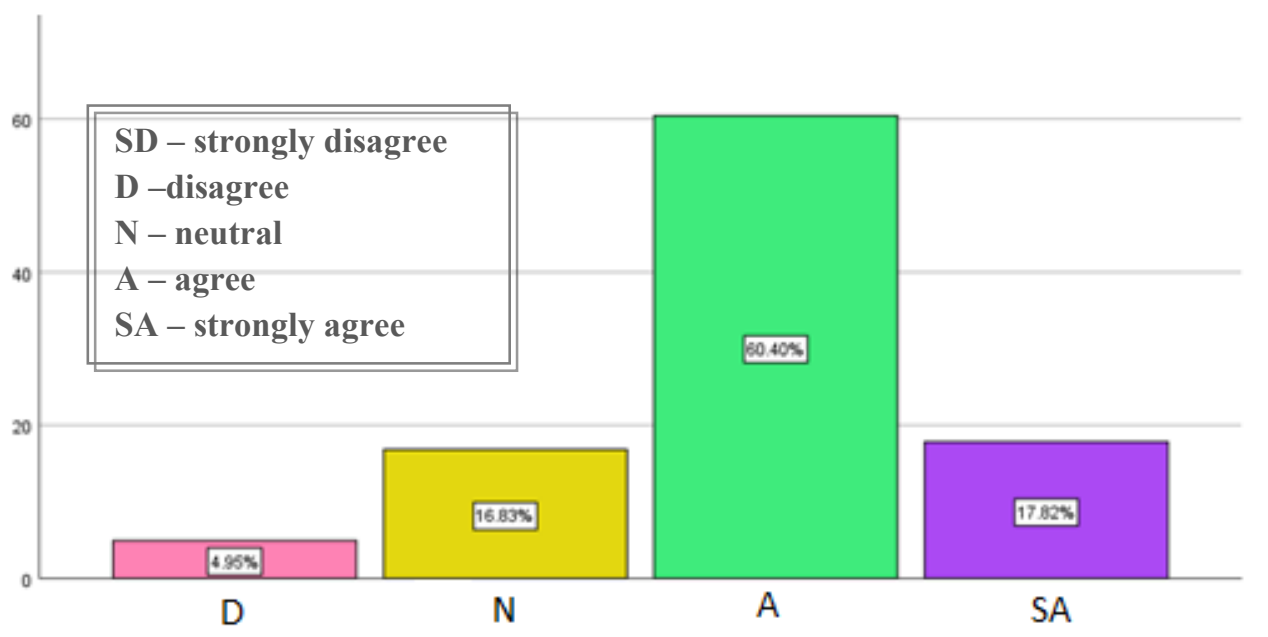

PICBE | 583

Figure 6. Knowledge management and best practices

Source: Authors' own research results after entering data in SPSS

The second hypothesis, which relates to the fact that there is a significant relationship between knowledge management and organizational performance, is also demonstrated.

However, although its value for organizational success has been well documented, few systematic studies have been conducted on how knowledge is activated and transferred in organizations and on their impact on organizational performance. For this reason, knowledge management theory is based on limited and often anecdotal evidence. This is particularly the case for knowledge transfer.

The purpose of knowledge transfer is to train a person to recognize and apply the knowledge acquired in previous tasks to new tasks or new areas. An efficient knowledge transfer system facilitates process learning for new tasks, for which little information is available.

$71.29 \%$ of employees agree that written sources (previously implemented project documentation, organizational procedures, instructions and other documented sources) are appropriate for successful knowledge transfer.

The definition of knowledge transfer concerns not only the improvement of transfer learning results, but also the process and the reasons for an effective transfer and the impact on organizational performance. I am interested in revealing the explicit knowledge that has been transferred between the source task and the target task and what is the impact on organizational performance. Still, exchanging knowledge with colleagues contributes to organizational performance and continuing education; according to the results of the questionnaire, $50.50 \%$ of employees fully agree with this aspect.

Project-based companies are advised to develop various learning mechanisms that improve the accumulation and transfer of knowledge. However, even if the importance of knowledge transfer and project-based learning remains increasingly important for companies, only a few companies have institutionalized the practices (mechanisms and processes) allowing to capture and disseminate knowledge in projects later. In addition, very few studies have established the effectiveness of knowledge and learning transfer mechanisms and processes within and between projects. There is the possibility of some appropriate learning mechanisms and processes for managing and transferring the accumulated knowledge between projects, and 
others are not the appropriate channels. If the appropriate mechanisms are neglected, the possibility of improving the performance of future projects is lacking, as well as the possibility of avoiding the repetition of the same errors.

In addition, knowledge transfer mechanisms and processes should be economically feasible. Cooper et al. (2002, p. 213) observe that "it remains for us to discern how to extract and disseminate systematically the lessons of management as we move from project to project. "

This fact means that the company plays a very important role in the performance of each employee who contributes to the achievement of excellent organizational performance, so assumption number three is demonstrated.

According to the study, a number of $49.57 \%$ of individuals agree that the company motivates employees with rewards to improve their performance, a factor which contributes to the achievement of superior organizational performance. We can also notice that $24.75 \%$ of the employees are in total agreement with this practice, therefore more than half of the employees of the shared services centre consider that the company plays a very important role on the performance. Figure 7 is representing the above-mentioned percentages.

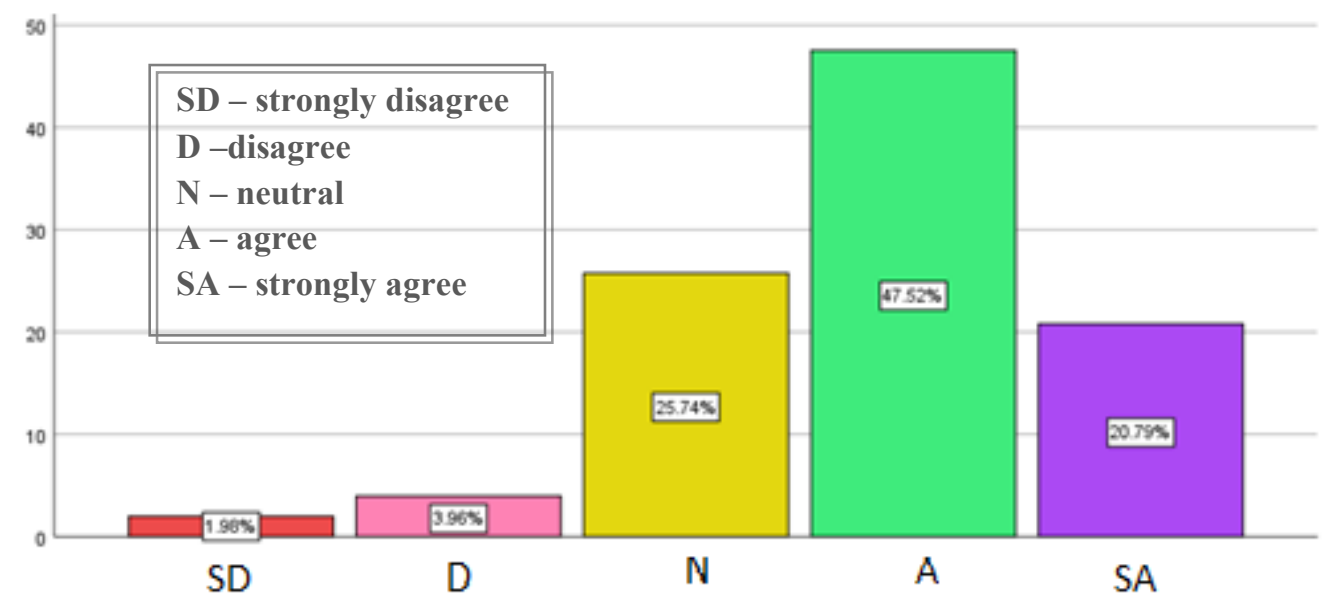

Figure 7. Practices to improve performance - company support

Source: Authors' own research results after entering data in SPSS

In a multicultural workplace, it is important and useful for the company to support the exchange of data, information and knowledge between organizational units in order to improve organizational performance. According to the study, $47.52 \%$ of employees agree with this statement.

The objective is to continuously improve the performance of the project. How knowledge is managed in society is crucial to gaining a competitive advantage.

Moreover, knowledge transfer has an impact on the vision of the company, management based on skills, continuous learning and performance of the company. The last hypothesis that I formulated is demonstrated- $50.50 \%$ of the employees consider that the company and its employees try to maintain a continuous training process to improve the organizational performance and the quality of the services provided.

To be able to show the importance of the transfer of knowledge on organizational performance I will present to you in the lines which follow the statistics with regard to the key 
indicators of performance for the team of human resources which is in charge with the administration of staff for the shared services centre's units located in North America, Denver and Montreal.

In order to demonstrate the impact of knowledge transfer on performance, I present an analysis by comparing the accuracy per team member to the following process: creation of employment contracts. I start with the presentation of the performance indicators for March 2018, before the training sessions in North America, then with the situation in June 2018, month during which all team members were trained and informed about the new procedures for job. In Figure 8 we can notice that, in March 2018 before the knowledge transfer session, the situation is dramatic. A very large part - $92 \%$ - of the employment contracts created for candidates from North America required adjustments. Only $8 \%$ of a total of 98 requests to create a work contract were issued in normal parameters and the quality of service was $100 \%$.

\section{Situation March 2018 - creation of employment contracts}

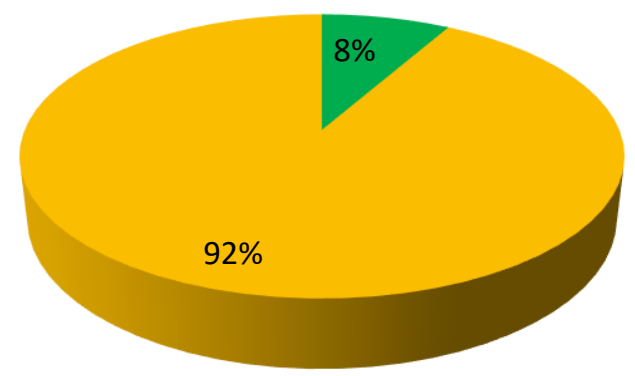

Figure 8. Situation March 2018 - creation of employment contracts

Source: Authors' own research results

On the other hand, in Figure 9 we can observe an improvement in the quality of service and on the performance of employees. With a situation of 139 requests for the creation of employment contracts that were launched in June 2018, 78\% were delivered without any errors. We can see that the transfer of knowledge had an impact on the performance of each employee, by comparing the situation in March 2018, with a very high percentage of errors on employment contracts $(92 \%)$, with the situation in June 2018, when the percentage that indicates errors is lowered to $22 \%$. 


\section{Situation June 2018 - creation of employment contracts}

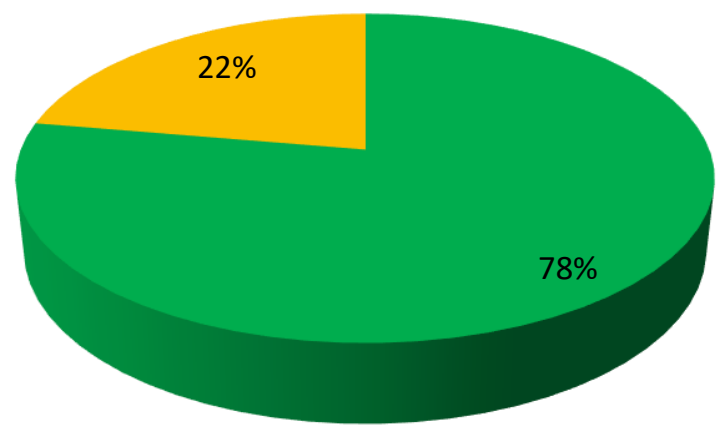

PICBE $\mid 586$

Figure 9. Situation June 2018 - creation of employment contracts

Source: Authors' own research results

After finalizing the knowledge transfer and with the help of the written procedures and steps to follow, the situation is changed.

\section{Conclusion}

Maximizing the usefulness of information offers opportunities to improve the knowledge discovery process. In the areas of machine learning and natural language basic processing, obtaining training labels is often costly, while a huge amount of untagged data is often available. Therefore, maximizing the usefulness of the information available on the labels would benefit the learning process. In light of this notion, this thesis studies the transfer of learning, emphasizing the reuse of acquired knowledge for other applicable tasks.

The intuition of knowledge transfer comes from the experience that it is easier to learn Spanish after having learned French or that it is easier to learn freestyle on ice after having learned ballet. In the context of machine learning, knowledge transfer is particularly useful when labeled data is absent or difficult to acquire.

The discussion of how to make effective use of available information facilitates the transfer of valuable knowledge for studies in the information sciences. We place knowledge transfer in an interdisciplinary perspective, a context of machine learning and information science.

The purpose of knowledge transfer is to discover explicit knowledge that can be effectively transferred between sources and target tasks as well as the balance between the objective of improving the performance of learning models.

This study strongly confirmed existing findings in the literature regarding the crucial importance of face-to-face interaction in knowledge transfer. It is clear that if other distribution channels, such as technology and written materials, play a role in the dissemination of knowledge, it is social interaction that serves as a catalyst for the transfer of knowledge. that is, the transfer of knowledge from a passive state to action. Indeed, face-to-face communication 
provides much more than just words or information. Through voice, gestures and body language, the recipient is able to assess the credibility of the source and develop their innate sense of reliability and credibility. This is an important first step in the knowledge transfer process. It is perfectly clear that the decision to take up a practice in another market is not taken in an emotionally neutral state and that this factor must be considered in the design of organizational knowledge management systems and processes.

PICBE | 587

The findings of the study revealed the large number, complexity and interconnectedness of the factors affecting knowledge transfer. When reflecting on these results, it is useful to think of the challenge of transferring knowledge between countries and cultures, such as a trip. Knowledge is conveyed during this journey by an individual who is influenced by a range of external and organizational factors, as well as by their own experiences as a vehicle for knowledge. Their life experiences can be positive or negative, as reflected in the different hills and valleys of the trip. As the journey continues, knowledge is modified, reduced, added and personalized. As knowledge is translated into actions, a number of indicators indicate that this transfer has taken place.

To encourage a greater transfer of knowledge and practices between countries, it is important to recruit and then develop managers with this objective in mind. The tool described above creates a "map" which can be useful in this regard. From a recruitment perspective, questions relating to the candidate's experience in a different cultural context, unstable environments and a driver of change would provide useful indicators of his interest in adopting knowledge outside his own cultural context. From a development perspective, if this type of experience was lacking among current and potential managers, appropriate development opportunities could be created through new roles, workstation exchanges, short-term targeted missions and projects.

\section{References}

Cooper, K. G., Lynesis, J. M. \& Bryant, B. J. (2002). Learning to learn, from past to future. s.1.: International Journal of Project Management.

Davenport, T. H. \&Prusak, L. (1998). Working Knowledge - How Organisations Manage What They Know. Boston: Harvard Business School Press.

Davenport, T. H., De Long, D. W. \& Beers, M. C. (1997).Successful knowledge management projects.

Davies, A. \& Hobday, M. (2005).The Business of Projects: Managing Innovation in Complex Products and Systems. s.1.: Cambridge University Press.

Dixon, N. (2000).Common Knowledge: How companies Thrive by Sharing What They Know. Boston: Harvard Business School Press.

Ibrahim, F. \& Reid, V. (2009). What is the value of Knowledge Management Practices? s.1. : Electronic Journal of Knowledge Management.

Leonard, D. (1998).Wellsprings of knowledge: Building and sustaining the sources of innovation. Boston: Harvard Business School Press.

Nonaka, I., \& Takeuchi, H. (1995). The knowledge-creating company. How Japanese companies create the dynamics of innovation. Oxford: Oxford University Press.

O'Dell, C. \& Grayson, C. J. (1998).If we only know what we know: The transfer of internal knowledge and best. New York: The Free Press. 
O'Dell, C. \& Jackson Grayson, C. (2001).Identifying and Transferring Internal Best Practices. Examining the business case for sharing best practices and the cultural organisational factors that help or hinder the process. Ways and Means White Paper-Issue-August 2001. URL: www.knowledgeboard.

Polanyi, M. (1966).The Tacit Dimension. London: Routledge \& Kegan Paul.

Probst, G., Raub, S. \&Romhardt, K. (2000).Managing Knowledge, Building Blocks for Success. New York: John Wiley\&Sons.

Prencipe, A. \& Tell, F. (2001).Inter-project learning: processes and outcomes of knowledge codification in project-based firms. s.l. : Research Policy.

Sowa, J., Ellis, G., Levinson, R. \& Rich, W. (1995).Conceptual structures, applications, implementation, and theory. s.l. : Third International Conference on Conceptual Structures, ICCS.

Tan, M. H., Narsurdin, E. (2011).Developing a knowledge strategy'. s.1. : California Management Review, Volume 4.

Van der Spek, R. \&Spojkervet, A. (1997).Knowledge Management: Dealing intelligently with Knowledge: Knowledge Management and its integrative elements, in eds initials Liebowitz \& initials Wilcox. s.1.: CRC Press.

Wiig, K. (1993).Knowledge Management Foundation. Texas: Schema Press. 